\title{
EFEITO OROGRÁFICO NA ILHA DE SÃO SEBASTIÃO (ILHABELA - SP)
}

\author{
MILANESI, Marcos Alexandre - maalex@terra.com.br \\ Departamento de Geografia - FFLCH / USP \\ GALVANI, Emerson - egalvani@usp.br \\ Laboratório de Climatologia e Biogeografia - Dep. Geografia - FFLCH / USP
}

\begin{abstract}
Resumo. O presente artigo tem como objetivo principal avaliar, na relação chuva versus relevo, a ocorrência da chuva orográfica a barlavento da Ilha de São Sebastião (Ilhabela - SP). Ao longo do Ano Hidrológico 2004 - 2005 foram coletados mensalmente dados da chuva da ilha, por meio da instalação de seis pluviômetros experimentais na Estrada de Castelhanos - de orientação $O$ - $L$, com $22 \mathrm{~km}$ de extensão e altitude máxima de 690m, em diferentes altitudes. Os dados receberam análise estatística descritiva e sua síntese conduziu, essencialmente, a três resultados: 1) 60,1\% do total de chuva coletado no período precipitou sobre a vertente exposta aos fluxos do setor SE (barlavento) confirmando a importância do relevo na sua distribuição; 2) descrição da sombra da chuva por meio da redução da pluviosidade a sotavento da ilha, onde os valores coletados foram $20 \%$ menores que os da vertente oposta, e; 3) identificação da chuva orográfica a $600 \mathrm{~m}$ de altitude (P7), onde os valores coletados foram invariavelmente mais elevados que os outros, em torno de $30 \%$ superiores, ultrapassando os $4000 \mathrm{~mm}$ anuais e acumulando um total mensal de 708,5 mm em março de 2005.

Palavras-chave: ilha, relevo, precipitação, chuva orográfica, sombra de chuva.
\end{abstract}

OROGRAPHIC EFFECT ON SÂO SEBASTIÂO ISLAND

Abstract. This article aims at assessing, in the relationship between rain versus relief, the occurrence of orographic precipitation on the windward side of the Island of São Sebastião (Ilhabela - SP). Throughout the Hydrologic Year 2004 - 2005 rainfall data were collected monthly, through the installation of six experimental rain gauges in Castelhanos Road - guidance W - E, with 22 km and maximum altitude of $690 \mathrm{~m}$, at different altitudes. The data were descriptive statistics and their synthesis led essentially to three results: 1) more than a half or $60.1 \%$ of the total rainfall collected was precipitated on the exposed side of the SE sector flows (windward) confirming the importance of the relief in its distribution; 2) rain shadow description through the reduction of rainfall in the lee of the island, where the values collected were $20 \%$ lower than the opposite side, and 3) identification of orographic rain at $600 \mathrm{~m}$ altitude $(P 7)$, where the collected values were invariably higher than the others, around 30\% higher, exceeding $4000 \mathrm{~mm}$ per year and reaching a total monthly of $708.5 \mathrm{~mm}$ in March 2005.

Keywords: island, relief, precipitation, orographic rain, rain shadow.

\section{Introdução}

Este artigo apresenta uma leitura das interações entre a chuva e a morfologia do relevo sobre as vertentes da Ilha de São Sebastião (Ilhabela - SP). De viés topoclimático, busca a individualização climatológica deste município frente a outros do litoral norte do Estado de São Paulo, a partir do reconhecimento do fenômeno da chuva orográfica, característico do litoral da região sudeste, marcadamente pela presença da Serra do Mar e pela atuação dos alísios.

Observa Milanesi (2007), que os efeitos orográficos do clima são quaisquer controles que exerce o relevo sobre os atributos do clima em uma determinada localidade. As interações entre essas duas componentes podem gerar perturbações naturais na dinâmica atmosférica regional e local de acordo com morfologia do relevo. De forma geral observa-se que independentemente do porte do relevo, este exerce algum notável controle sobre as dinâmicas climáticas locais. É perceptível a gama de influências conhecidas do relevo sobre os atributos do clima. As resultantes destes processos interativos entre a atmosfera e a crosta terrestre são os gradientes de temperatura e pressão, a obstrução e bifurcação de ventos e a geração de brisas e nuvens, além da chuva orográfica e da sombra de chuva.

Conforme Ayoade (1988), a gênese da chuva orográfica se configura num fluxo de vento úmido que ao transpor uma rugosidade do relevo, tem sua coluna de ar em elevação com perda de temperatura sem troca com o meio e gerando nebulosidade que, possivelmente se converterá em chuva até uma determinada 
altitude, na encosta ativa do processo (barlavento). Posteriormente à transposição da linha de cumeeira, o fluxo de ar agora descende, aquece e gera, a sotavento, uma atmosfera relativamente seca (fenômeno da sombra de chuva).

Smith (1979) descreve os três mecanismos da precipitação e intensificação orográfica:

- Autoconversão: modelo clássico da chuva orográfica. Resulta da elevação forçada do fluxo de ar pelas vertentes da montanha. Se as condições atmosféricas forem constantes, o crescimento das gotas deverá ser similar em qualquer ponto da montanha, provocando chuva com característica temporal uniforme. Processo típico ação da brisa marinha sobre o relevo da zona costeira.

- Convecção disparada: ocorre na vertente mais ensolarada da montanha (leste) em função da quantidade de radiação solar absorvida ao longo do dia, quando nuvens da família dos cumulus, de grande desenvolvimento vertical são ativadas. Não apresenta uma distribuição vertical da chuva marcante na encosta, porém, a vegetação pode atuar como fornecedora da umidade em maiores altitudes.

- Semeador-alimentador (seeder-feeder): pressupõe a ocorrência de nuvens mais altas precipitando (seeder) sobre nuvens mais baixas (feeder) ocorrentes pela ascensão da coluna de ar, aumentando a colisão entre as gotas. Como no caso da passagem de um sistema frontal (frente-fria) sobre nebulosidade pré-existente de altitude inferior. A liberação da massa de água para o ambiente facilita a formação de nuvens, com bases aproximadamente entre 50 e 200 m acima do nível da superfície, possibilitando a intensificação da chuva orográfica.

Leopold (1949) esclarece parte da circulação atmosférica do arquipélago estadunidense do Havaí, quando descreve os principais tipos de interações entre a brisa marinha e os alísios predominantes, enfatizando o controle do relevo na distribuição espacial da chuva. Em número de quatro, cada tipologia é denominada em acordo com a ilha em que ocorre e seus processos guardam certa semelhança com a área de estudo, considerando que o Havaí fica no hemisfério norte e que os alísios lá sopram de nordeste. Os tipos Lanai, Maui, Mauna Kea e Kona variam entre si quanto à morfologia do relevo e quanto à intensidade dos ventos presentes no processo podendo ou não gerar chuva orográfica. No Brasil, França (1954) e Conti (1975) realizaram os estudos virais acerca da climatologia da ilha e da região do Litoral Norte; corroboram entre si quanto à existência da sombra de chuva no sotavento da ilha (vertente do canal de São Sebastião) e de sua possível extensão para noroeste (NO) - sudoeste (SO) do município de Caraguatatuba, conforme a hipótese de Sant'Anna Neto (1990), que atribui papel relevante também à Serra do Dom em sua formação.

Dado o exposto, são considerados objetivos desta pesquisa, aqueles baseados na investigação da relação pluviosidade $x$ orografia. De forma ampla, questionar e avaliar a dinâmica da chuva sob o controle do relevo, na Ilha de São Sebastião.

- Identificar a ocorrência das chuvas orográficas;

- Evidenciar outros efeitos causados pelo relevo como a sombra de chuva;

- Entender o grau de influência da ilha na distribuição espacial e temporal da chuva local;

- Encontrar uma resposta da relação chuva versus relevo, na atuação dos principais tipos de tempo e na ocorrência de eventos extremos; 


\section{Área de Estudo}

Segundo Monteiro (1973) o clima do litoral do estado de São Paulo é a resultante da interação entre três grandes controles atmosféricos de ordem regional: a circulação secundária, sob a forma dos frequentes embates entre as três massas de ar mais atuantes na região (massa tropical atlântica, massa tropical continental e a massa polar atlântica); o oceano: matéria-prima da umidade disponível e o relevo (Serra do Mar, de orientação SO-NE: atua como barreira aos ventos úmidos predominantes de SE). Além da sujeição da área aos tipos de tempo derivados principalmente da atuação oscilante entre os sistemas frontais, como a passagem da frente-fria, que é responsável por boa parte da chuva precipitada no estado e no litoral, e os sistemas intertropicais de bom tempo.

Inserida neste contexto climático regional, localiza-se a Ilha de São Sebastião no município de Ilhabela, no Litoral Norte do Estado de São Paulo, sob as coordenadas geográficas latitude $23^{\circ} 46^{\prime} 28^{\prime \prime}$ Sul e longitude $45^{\circ} 21^{\prime} 20^{\prime \prime}$ Oeste, a uma distância de $210 \mathrm{~km}$ da capital paulista. Separa-se do continente pelo Canal de São Sebastião de largura aproximada de $8 \mathrm{~km}$, sendo limítrofe com os municípios de São Sebastião e Caraguatatuba.

De orientação geral SO-NE, a Ilha de São Sebastião possui área de $347,54 \mathrm{~km}^{2}$ (IBGE, 2011), sendo a distância entre seus pontos extremos (Ponta das Canas, norte e Ponta do Boi, sul) de $28 \mathrm{~km}$, e largura variável. Apresenta relevo planáltico em torno de $3 / 4$ de seu território e pequenas áreas de planícies litorâneas - a do Perequê, na face voltada para o canal e Castelhanos (na face leste) são as maiores - Cruz (1986) as denomina planícies de bolso, dada sua área reduzida. Seus pontos de maior altitude atingem os $1379 \mathrm{~m}$, no Pico de São Sebastião (maciço sul) e $1250 \mathrm{~m}$, no Pico do Ramalho (maciço norte) e, denotam vertentes de acentuada inclinação, em torno de $30 \%$. A vegetação que recobre a ilha - importante componente da gênese pluvial por meio da transpiração - é de Mata Atlântica (pluvial de encosta) e guarda em seu interior espécies endêmicas de vegetais e animais que fazem parte, dependendo ou determinando a dinâmica ecológica da paisagem ilhéu. (Figura 1).

Seu sistema viário tem duas importantes rodovias, a SP-131, de diversas designações, que liga o norte ao sul (urbanizado - defronte ao canal) e a, agora, Estrada Parque de Castelhanos (SP-231/004), única via de acesso terrestre que corta a ilha de oeste a leste e integra as comunidades caiçaras de leste à infraestrutura urbana do município.

A estrada, de terra, de $22 \mathrm{~km}$ (e $690 \mathrm{~m}$ de altitude máxima) é atrativo turístico regional e atravessa o Parque Estadual de Ilhabela (PEIb) em $17 \mathrm{~km}$, recebendo com frequência veículos e pedestres. O uso desta via é altamente dependente do regime das chuvas e da sua exploração econômica: na alta temporada o movimento atinge 300 veículos por dia, algo em torno de 2.500 pessoas por mês (Prefeitura Municipal de Ilhabela, 2011); também é no verão que os maiores montantes de chuva são precipitados na ilha e na região. O quadro da inviabilidade de sua transposição é real, sendo por vezes, necessária sua interdição, dado o número de ocorrências de movimentos de massa, queda de árvores e atoleiros resultantes em sua face leste. 


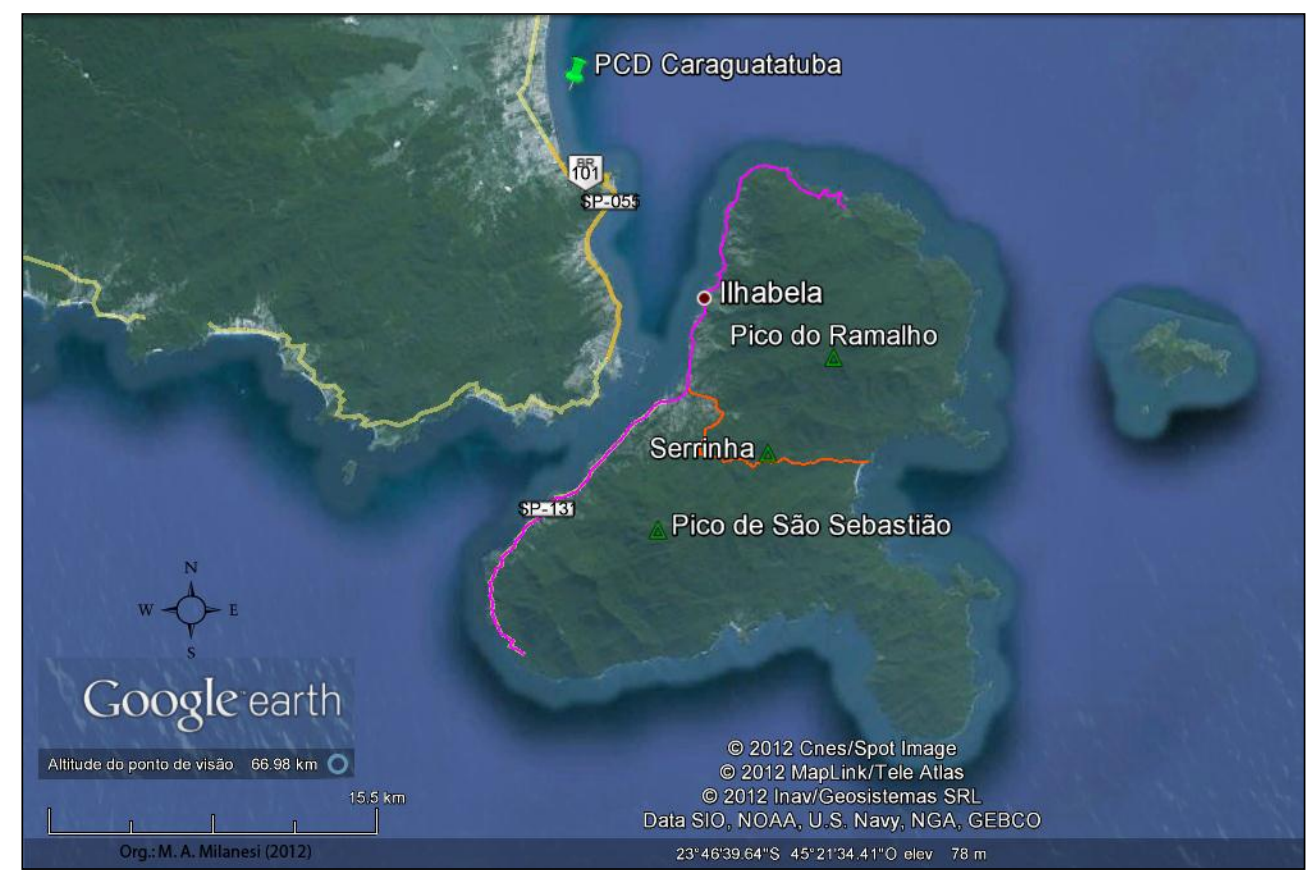

Figura 1

A Ilha de São Sebastião e a Estrada de Castelhanos (laranja)

Fonte: Google Earth (2012)

Segundo o IBGE (2002), a região do litoral norte é dominada pelo clima Tropical do Brasil Central - subquente (média entre 15 e $18^{\circ} \mathrm{C}$ em ao menos 1 mês por ano), superúmido, sem seca, assim como a vertente leste da ilha e da Serra do Mar, ambas expostas (barlavento) aos fluxos aéreos dominantes de sudeste. Porém, tanto em altitude (no continente) como a sotavento da ilha domina o subtipo mesotérmico brando (média entre 10 e $15^{\circ} \mathrm{C}$ ), superúmido, subseco.

A $3^{a}$ normal climatológica (1961-1990) da estação meteorológica Ubatuba, do INMET ( $50 \mathrm{~km}$ a NE da ilha), dispõe da seguinte climatologia média para a região: temperatura em torno dos $20^{\circ} \mathrm{C}$, entre os $25^{\circ} \mathrm{C}$ no verão e os $18^{\circ} \mathrm{C}$ no inverno e chuvas relativamente bem distribuídas ao longo do ano $(2644,5 \mathrm{~mm})$, porém, concentradas no verão variando entre $84 \mathrm{~mm}$ (junho) a 365,8 mm em janeiro, como apresentado na figura 2.

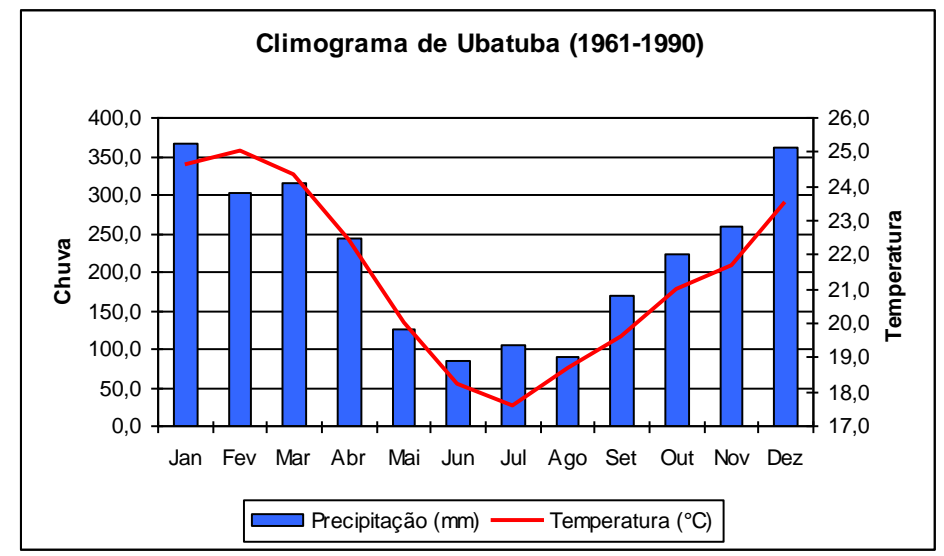

Figura 2

$3^{a}$ Normal Climatológica para o município de Ubatuba

Fonte: INMET (1992) - Org. M.A. Milanesi (2012) 
Em consideração ao apresentado, o município de Ilhabela, SP parece estar numa situação peculiar reunindo, então, condições climatológicas e geomorfológicas favoráveis à formação da chuva orográfica. Partindo do princípio de certa regularidade na distribuição espacial desta tipologia de precipitação e da possibilidade de seu mapeamento, sugere-se considerá-la nos processos de planejamento e ordenação territorial: planos diretores municipais e planos de manejo ambiental.

\section{Materiais e procedimentos}

Foram utilizados os dados de dois tipos diferentes de pluviômetros, um pertencendo a uma estação automática, a Plataforma de Coleta de Dados (PCD) Caraguatatuba, de responsabilidade do CPTEC/INPE e, outro, um conjunto de seis pluviômetros experimentais de Milanesi e Galvani (2005) instalados na extensão da Estrada de Castelhanos (três na vertente voltada para o continente - sotavento e, três na vertente voltada para o oceano exposta aos ventos predominantes - barlavento) em três faixas de altitudes contemplando planície, meia vertente e adjacências do divisor de águas (Figura 3).

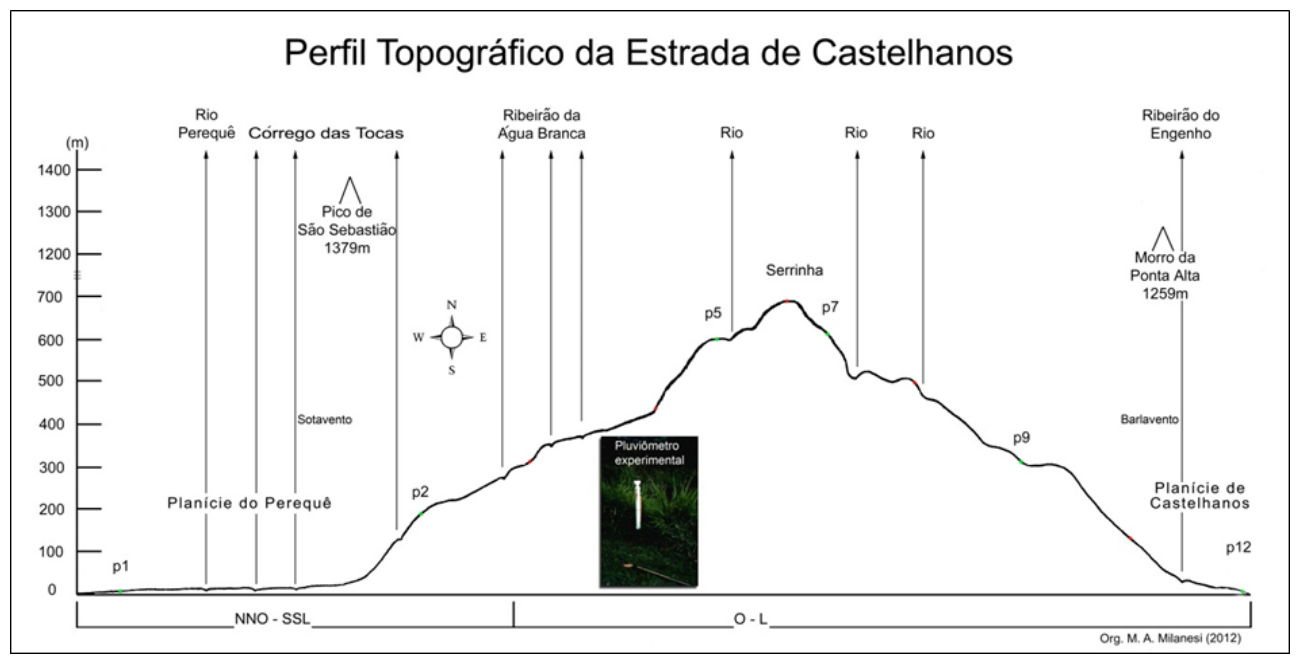

Figura 3

Perfil topográfico da Estrada de Castelhanos e pontos de instalação dos pluviômetros experimentais

Fonte: Milanesi (2007)

A PCD Caraguatatuba apresenta uma série de sensores que registram, de três em três horas, automaticamente, as variações horárias de treze atributos climáticos, entre os quais, a chuva que foi nosso parâmetro com relação à chuva observada na ilha.

Os pluviômetros experimentais foram desenvolvidos de para serem equipamentos totalizadores mensais dos dados de chuva. Para tanto, realizaram-se 14 trabalhos de campo: dois para montagem e desmontagem do equipamento e 12 para o registro dos dados. Estes últimos em todo o dia 10 de cada mês do Ano Hidrológico 2004/2005 (AH04/05) - de outubro de 2004 a setembro de 2005.

Os dados coletados receberam análise estatística descritiva básica: definição das medidas de tendência central, dispersão e correlacionados entre si posteriormente, comparadas e estabelecidas as devidas relações, os dados foram organizados de forma gráfica na tentativa de uma espacialização da 
chuva, porém, que extrapolasse o viés climatológico, possibilitando seu uso em atividades de planejamento e gestão do espaço.

Ainda foram utilizadas as informações adicionais da Revista Climanálise do CPTEC/INPE para a contabilização das situações sinóticas formadoras de precipitação.

\section{Resultados e Discussão}

A análise mais superficial do banco de dados aponta para uma média climatológica da precipitação anual em torno dos 3015,0 mm (AH 04/05), o que faria com que Ilhabela pudesse ser considerado o município mais chuvoso do litoral norte paulista, em comparação com a $3^{a}$ Normal Climatológica de Ubatuba - 2644,5 mm (INMET, 1992), contradizendo outras fontes consultadas como o DAEE (2011) que indica a média de $1509,0 \mathrm{~mm} /$ ano no posto Ilhabela.

Porém, quando comparado com a PCD Caraguatatuba, no mesmo período, é fundamentalmente superior ao valor deste, $1468,8 \mathrm{~mm}$ - ou seja, de maneira geral, chove mais em Ilhabela, reafirmando-se a influência de seu relevo na confirmação da existência da sombra de chuva e na distribuição da chuva regional conforme a hipótese de Sant'Anna Neto (1990). Considerando a altura anual da chuva da PCD Caraguatatuba, a média da chuva observada nos trabalhos de campo em Ilhabela chega a ser 2 a 3 vezes maior, como em fevereiro de 2005, quando foram anotados 40,3 mm no continente e 137,5 mm na ilha (Figura 4).

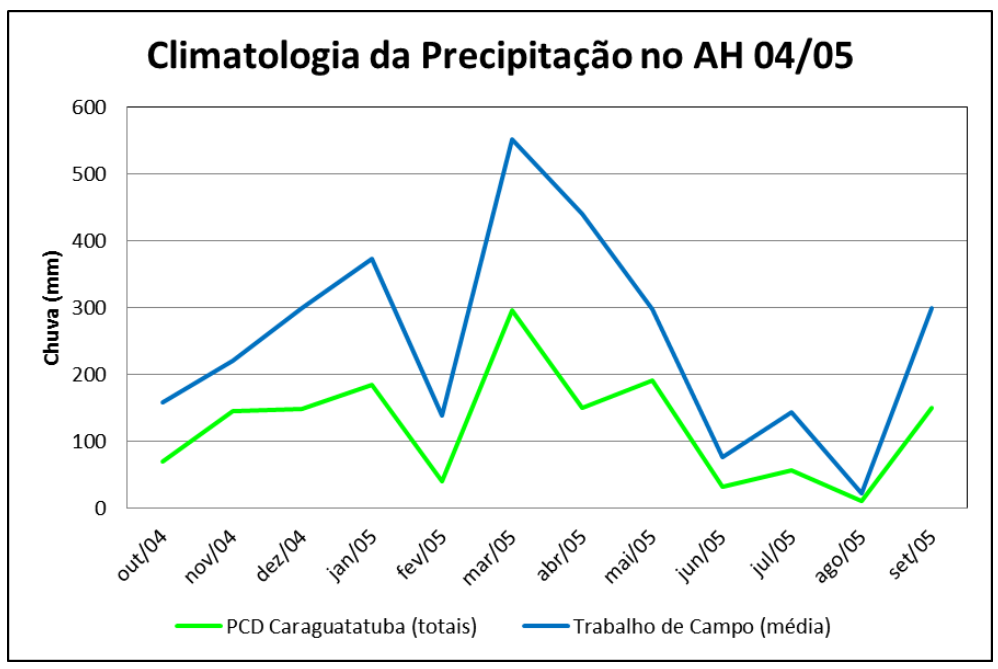

Figura 4

Climatologia da precipitação no Ano Hidrológico 2004/2005 em Caraguatatuba e Ilhabela

Org. M. A. Milanesi (2012)

A análise temporal dos dados da chuva revela homogeneidade na distribuição dos eventos entre os postos pluviométricos monitorados e são consoantes com o regime regional. Este regime caracteriza-se de chuvas razoavelmente distribuídas ao longo do ano, sem apresentar uma estação realmente seca, participando o inverno com 15,3 \% dos totais sazonais, contudo, sendo 0 período chuvoso concentrado nos meses do verão $(35,3 \%)$. Primavera e outono - estações transicionais contribuíram com uma média aproximada de $24,5 \%$ cada uma. O mês mais chuvoso foi março de 2005 , com $18,3 \%$ do total observado $(3313,9 \mathrm{~mm})$ possivelmente pela atuação da Zona de Convergência 
do Atlântico Sul em pelo menos 40 \% dos dias e cinco sistemas frontais, segundo o Boletim Climanálise, do INPE. Já o menos úmido foi agosto de 2005 com 0,7 \% (125,3 mm), com baixa atuação de sistemas atmosféricos portadores de umidade.

Interessante registrar a dinâmica mensal de dois pluviômetros em especial: P5 (600 m de altitude) na vertente voltada para o canal e P9 (290 m de altitude, a barlavento). Ambos registraram quantidades de chuva extremamente semelhantes em janeiro e fevereiro e, de junho a agosto não apresentando diferenças superiores a $4,5 \mathrm{~mm}$. Nos outros meses as diferenças tornam-se sensíveis: P5 teve uma frequência maior de meses chuvosos (Out., Nov., Dez. de 2004 e Set. de 2005), porém, com menores valores acumulados $(1258,5$ $\mathrm{mm}$ ) contra P9 que contou com chuva $(1611,5 \mathrm{~mm})$ em março, abril e maio de 2004. Possivelmente essas diferenças devem estar tanto relacionadas às estações do ano quanto à altitude ou vertente na qual ocorrem e necessitam de mais detalhamentos para sua compreensão. (Figura 5).

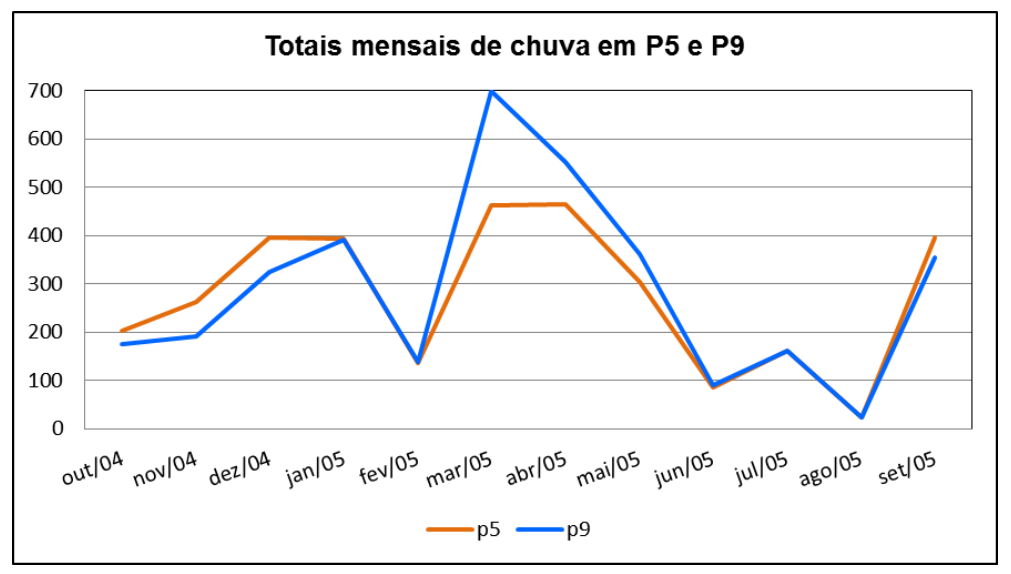

Figura 5

Totais mensais de chuva nos pluviômetros P5 e P9

Org. M.A. Milanesi (2012)

Considerando que os pluviômetros estão sob o mesmo regime pluviométrico, sem com isso, apresentar variações, a princípio, significativas na temporalidade dos eventos de chuva, somos levados a acreditar que o relevo de Ilhabela não exerce influência, do ponto de vista sinótico, sobre o avanço de uma massa de ar, sendo, porém, inevitável a interação de ambos na constituição dos climas locais. Lembra Conti (1975) quanto à chuva orográfica, que esta é fruto, não unicamente, da relação da chuva com o relevo, mas resultado de uma interação dinâmica que considera além destes dois fatores, aqueles outros de caráter local.

A análise espacial dos dados de chuva apresenta esse dinamismo único, propiciado pelo relevo, que num primeiro momento é determinante mais por sua orientação geral do que pela altitude. Como já observado, a ilha possui orientação geral SO-NE, o que Ihe confere duas encostas principais: barlavento - vertente ativa do processo orográfico, aqui com fachada oriental de SE e, sotavento - vertente oposta. As encostas de SE, tanto na ilha como no continente, na Serra do Mar, são muito úmidas, pois a acumulam devido ao transporte diário que recebem dos alísios e das brisas marinhas. Portanto seu barlavento é essencial na distribuição da umidade e da chuva que lá ocorrem, logo é um dos fatores locais a se considerar numa possível construção de uma feição climática municipal. 
E essa característica natural da morfologia da ilha, o aspecto montanhoso, as vertentes opostas, é muito bem demonstrada quando da análise dos totais mensais da chuva organizados por vertentes: a barlavento da ilha choveu em torno de $60,1 \%$ dos totais do $\mathrm{AH} 04 / 05$, enquanto a sotavento, os totais foram de $39,9 \%$.

A figura 6 apresenta os totais sazonais desse ano hidrológico que refletem a situação de exposição e abrigo aos fluxos aéreos dos pluviômetros, confirmando a existência do fenômeno sombra de chuva, bastante abordado na literatura. A vertente voltada para o continente apresenta-se em média, $20 \%$ menos úmida que o lado oceânico, sendo que no $1^{\circ}$ trimestre do ano hidrológico (primavera) a diferença foi de $4 \%$, no verão foi de $6 \%$, com $7,5 \%$ no outono e, a menor diferença no inverno com 2,6\%.

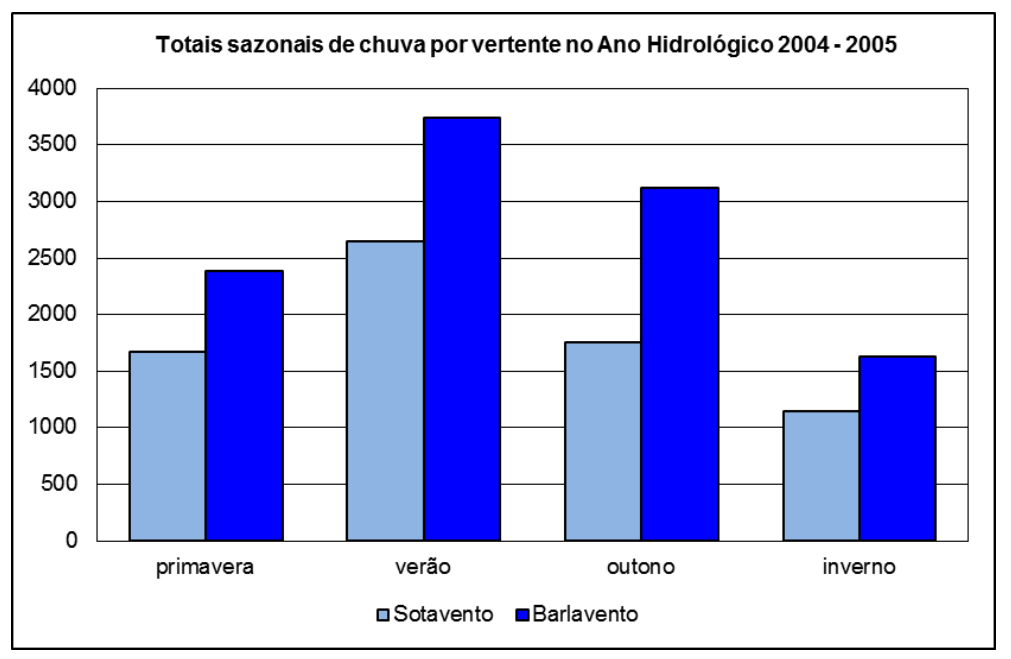

Figura 6

Totais sazonais da chuva (em $\mathrm{mm}$ ) por vertente e por estações do ano Org. M.A. Milanesi (2012)

A influência do relevo da ilha na constituição da sombra de chuva vai além do próprio território da ilha. Foi demonstrado anteriormente que, de maneira geral, chove mais em Ilhabela do que em Caraguatatuba. Porém, observando atentamente os desvios relativos dos pluviômetros em relação aos dados da PCD Caraguatatuba percebemos que em três meses do AH 04/05 este último suplantou os dados de P1, na ilha. Em dezembro de 2004 choveu mais no continente em torno de $30 \%$, em junho de 2005 em torno de $15 \%$ e setembro (2005), $10 \%$ - possivelmente fruto de alguma atividade convectiva ou de circulação invertida. Este P1, que acumulou os menores volumes de chuva da ilha, dada a sua situação de proximidade ao sopé da morraria do maciço norte na vertente continental pode francamente ter causado esse aprofundamento da sombra de chuva. No entanto, essa dinâmica chuva $x$ relevo $x$ sombra sugere a existência de algo mais complexo: além da sombra de chuva, uma penumbra de chuva - tal qual um eclipse.

Ainda que o relevo atue como obstáculo aos ventos e possa ser reconhecido como importante controle na distribuição da umidade e da precipitação local, a componente altitude não pode ser deixada de lado, visto que é em até determinada altitude que ocorre o processo de intensificação da chuva por mecanismos orográficos. No cômputo dos valores de P7, a $600 \mathrm{~m}$ da altitude na vertente oceânica - o pluviômetro mais chuvoso da ilha acumulou 4371,7mm ou $24,2 \%$ de toda a chuva coletada no AH 04/05. Resultado da escalada da corrente de ar úmida sobre o barlavento da ilha: em P12 ( $3 \mathrm{~m}$ de altitude) é 
possivelmente o pluviômetro que recebe as primeiras chuvas se vindas entre o sul e o leste, foi registrado 16,8 \% (3036,8 mm) e em P9 (290 m de altitude), a contribuição foi de $3462,5 \mathrm{~mm}$ ou $19,1 \%$; somando o barlavento da ilha: $60,1 \%$ sobre o total do universo coletado. Ainda P7, registrou a maior e a menor altura mensal de chuva: 708,5 mm em março de 2005 e, 13 mm em agosto de 2005. No sotavento da ilha, os volumes de chuva registrados diminuem paulatinamente, pois à medida que o fluxo de ar desce a vertente, resseca, segundo o efeito de Fohen, enquanto se afasta da morraria da ilha. 0 comportamento da chuva em P5 - 600 m de altitude na vertente continental, é bem semelhante ao da vertente chuvosa, é o 30 mais chuvoso com 3289,9 mm no ano ou $18,2 \%$ do total anual, porém, aproximando-se mais de P9 do que de P7, como já visto antes.

O controle que a morfologia do relevo da ilha exerce sobre a atmosfera ao seu redor pode ser perfeitamente demonstrado de forma gráfica como expressa a figura 7, na distribuição espacial da chuva na Estrada de Castelhanos onde, em função da altitude e das vertentes, os pluviômetros foram instalados. É composta do elemento aéreo (fluxos úmidos de SE), do obstáculo do relevo (o perfil topográfico da Estrada de Castelhanos, uma síntese do relevo ilha), dos totais anuais de chuvas para cada um dos seis pluviômetros experimentais utilizados aqui neste trabalho e da participação relativa de cada vertente na distribuição da chuva. Observam-se com clareza três processos de participação orográfica: o barlavento que apresenta os maiores volumes de chuva, culminando na altitude de $600 \mathrm{~m}$ com a intensificação da chuva e a correspondente sombra de chuva no sotavento da ilha, a célula de atmosfera seca a que se refere Conti (1975).

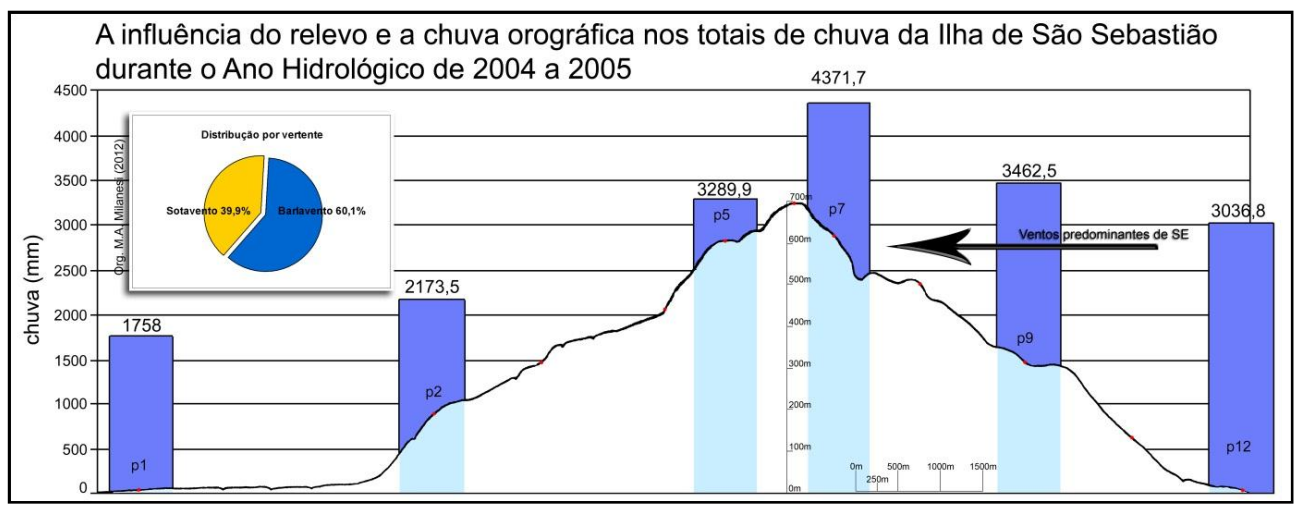

Figura 7

Totais anuais de chuva na Ilha de São Sebastião no AH 04/05 Org. M.A. Milanesi (2012)

Ainda em consideração aos valores totais de chuva da ilha, foi calculada sua correlação linear com a altitude na tentativa de encontrar uma taxa, ao menos especulativa, sobre o aumento e redução da pluviosidade conforme a altitude: o gradiente pluviométrico (Figura 8 ).

A análise da reta de regressão descreve elevada correlação em ambas as vertentes entre a chuva e a altitude, que reforça a influência do relevo na relação. No barlavento a correlação foi de $R^{2}=0,99$ e a sotavento foi de $R^{2}=$ 0,96 . Os gradientes pluviométricos calculados apontam para acréscimo de chuva na vertente exposta da ordem de 2,25 $\mathrm{mm}$ por metro de altitude e decréscimo dos valores observados a sotavento da ordem de $2,5 \mathrm{~mm}$ de chuva por metro. 


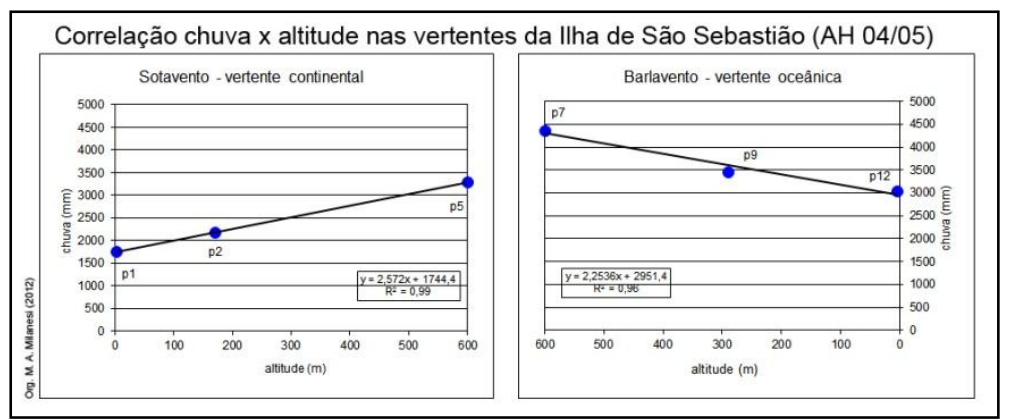

Figura 8

Correlação entre chuva e altitude nas vertentes opostas da Ilha de São Sebastião.

Também foi realizada uma distribuição de frequências dos eventos chuvosos segundo oito classes de chuva (a cada $100 \mathrm{~mm}$, variando de 0 a $800 \mathrm{~mm}$ mensais) por posto, com o intuito de se avaliar quais os volumes mais comuns e em que altitudes aconteciam. Observa-se tanto a redução do número de eventos de chuva como o aumento da quantidade precipitada com relação à elevação do relevo.

A análise da distribuição de frequências (Figura 9) conduz ao entendimento de que:

- 51,4 \% (37 dos 72 eventos) de todos os eventos de chuva da ilha precipitaram entre 0 e $200 \mathrm{~mm}$ mensais preferencialmente no outonoinverno, sem distinção de vertentes sendo que a maioria dos eventos (24) está entre os 101 e $200 \mathrm{~mm}$;

- Outros 40,3 \% (29 eventos) correspondem a precipitações entre os 201 e os $500 \mathrm{~mm}$ mensais coletados na primavera-verão, na vertente oceânica e em P5, sendo que a concentração de eventos se deu no intervalo entre os 301-400 mm, com 12 ocorrências de eventos, e;

- Acima dos $501 \mathrm{~mm}$ até $800 \mathrm{~mm}$, temos 8,3\% dos eventos (6), concentrados em 3 eventos de quantidades entre os $601-700 \mathrm{~mm}$ mensais em P7 e P9 e um evento de 708,5 mm em P7.

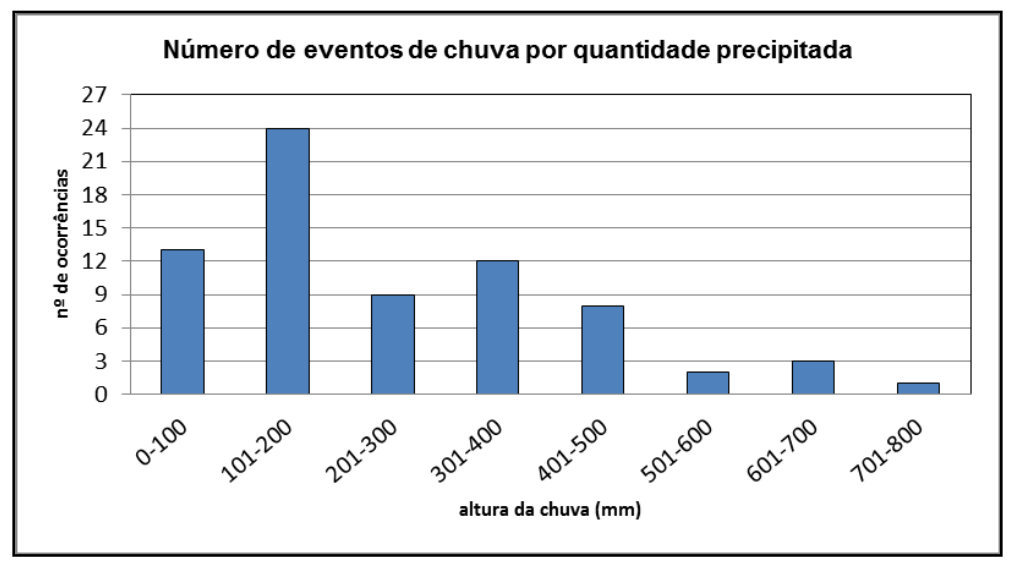

Figura 9

Distribuição de frequência dos eventos chuvosos e valores precipitados mensais

Org. M. A. Milanesi (2012) 
Assim em P1 prevalecem as precipitações entre 101-200 mm, em P2 também prevalece esse valor entre os $101-200 \mathrm{~mm}$, em P5 os valores dominantes estão entre os 301-400 mm, valores superiores a 401-500 mm são comuns em P7, porém, apresentando eventos de chuva com valores superiores a $700 \mathrm{~mm}$ mensais, em P9 os valores principais estão entre os 101-200 mm e entre os 301-400 mm com 4 eventos cada categoria e, por último, P12 também com dominância dos valores igualmente vistos em P9, porém, com 3 eventos cada.

\section{Conclusões}

Durante o andamento dessa pesquisa foi discutida a existência de efeitos orográficos na formação e distribuição da chuva da Ilha de São Sebastião, suas relações com a morfologia do relevo e senão respondidas, abordadas as questões propostas com pertinência.

Um fator limitante está evidente na baixa densidade de postos climatológicos oficiais que possibilitam pouca compreensão da dinâmica climática na Ilha de São Sebastião.

Outro fator limitante tem relação com a periodicidade da coleta de dados nos trabalhos de campo. Os dados mensais respondem a uma parcela introdutória do questionamento levantado, contudo, deixam a desejar quanto à análise em outras escalas temporais, por exemplo, que permitam a identificação da tipologia da chuva orográfica, que dada sua excepcionalidade, depende de informações horárias.

Os procedimentos e métodos utilizados foram julgados adequados para as conclusões aqui alcançadas. Os modelos propostos por Leopold (1949) e Smith (1979), acerca da interação entre a brisa marinha, os ventos predominantes e aqueles acerca da tipologia das chuvas orográficas foram considerados de extrema relevância, para uma área com demanda de dados sistematizados.

Os pluviômetros experimentais cumpriram com sua função de captar os volumes de precipitação na Estrada de Castelhanos, porém, para sua otimização devem ser redimensionados.

O que se conclui de fato sobre a relação chuva $x$ relevo considerando o fluxo de ar predominante em Ilhabela é que:

- Chove mais a barlavento: os três pluviômetros dessa vertente acumularam $60,1 \%$ dos totais, os volumes de chuva mais comuns foram aqueles acima dos $300 \mathrm{~mm} / \mathrm{mês}$ e a esta foi a única vertente que registrou precipitações superiores a $500 \mathrm{~mm} / \mathrm{mês}$; além de chover mais nessa vertente, em quaisquer estações do ano, numa média de $25 \%$. Considerando essa situação, chove mais na ilha que no continente.

- Chove mais em altitude: P7 (barlavento, a $600 \mathrm{~m}$ de altitude), somou sozinho aproximadamente $25 \%$ da precipitação geral e é o posto mais chuvoso (acumulou 1334,9 mm a mais que P12 - $5 \mathrm{~m}$ ), $44 \%$ de acréscimo; aqui, acima dos $300 \mathrm{~m}$ de altitude, são mais comuns as chuvas superiores aos $500 \mathrm{~mm} / \mathrm{mês}$ até o máximo mensal observado de $708,5 \mathrm{~mm}$ (março de 2005). Dessa forma, identificando a chuva orográfica;

- Há redução da chuva a sotavento: os valores coletados somaram 39,9\% dos totais - $20 \%$ inferiores aos da vertente oposta e descrevem a sombra da chuva; as precipitações mais comuns são aquelas abaixo dos $400 \mathrm{~mm} / \mathrm{mês}$ e não apresentou registros de chuva superiores a 500 $\mathrm{mm} / \mathrm{mês}$;

- Chove menos em P1: o posto menos chuvoso, fica na planície do Perequê a $3 \mathrm{~m}$ de altitude, faceado para o canal bem ao sopé da morraria da ilha, apresentou os menores valores coletados, inclusive mais baixos que a PCD Caraguatatuba em alguns meses o que sugere a 
formação de uma área de transição dentro da zona da sombra da chuva: um entorno (penumbra) onde estaria a PCD Caraguatatuba e uma área central (sombra), sem dimensionamento definido, encabeçada por P1.

\section{Referências bibliográficas}

.AYOADE, J.O. Introdução à Climatologia para os trópicos. 2a. ed. São Paulo: Difel, 1988.

.CONTI, J.B. Circulação secundária e efeito orográfico na gênese das chuvas na região lesnordeste paulista. Tese (Doutorado). Instituto de Geografia, Universidade de São Paulo, São Paulo, 1975.

.CRUZ, O. A Serra do Mar e a preservação de suas vertentes. Revista Orientação, n7, São Paulo, 1986, 198p.

.FRANÇA, A. A Ilha de São Sebastião - Estudo de Geografia Humana. Tese (Doutorado). Faculdade de Filosofia Ciências e Letras, Universidade de São Paulo, São Paulo, 1954.

.INSTITUTO NACIONAL DE METEOROLOGIA (INMET). Normais climatológicas 1961-1990. Brasília. 1992.

.LEOPOLD, L. B. The interaction of trade wind and e sea breeze. Journal of Meteorology, Hawaii, v. 6, p. 312-320, 1949.

.MILANESI, M.A.; GALVANI, E. Pluviômetro experimental para localidades remotas. In: Simpósio Brasileiro de Geografia Física Aplicada, 11, São Paulo. Anais... São Paulo, 2005. 1 CD-ROM.

.MILANESI, M.A. Avaliação do efeito orográfico na pluviometria de vertentes opostas da Ilha de São Sebastião (Ilhabela - SP). 2007. 150pags. Dissertação (mestrado em Geografia Física). USP/FFLCH/DG, São Paulo, 14/set/2007.

.MONTEIRO, C.A.F. A dinâmica climática e as chuvas do Estado de São Paulo: estudo geográfico em forma de atlas. São Paulo, USP, Instituto de Geografia, 1973. 129p.

.SANT'ANNA NETO, J.L. Ritmo climático e a gênese das chuvas na zona costeira paulista. São Paulo, SP. Dissertação (Mestrado). Faculdade de Filosofia Letras e Ciências Humanas, Universidade de São Paulo, São Paulo, 1990.

.SMITH, R.B. The influence of mountains on the atmosphere. B. Saltzman, Ed. Advances in Geophysics. New Haven, v. 21, p.87-230. 1979.

\section{Referências Eletrônicas}

.DEPARTAMENTO DE ÁGUAS E ENERGIA ELÉTRICA (DAEE - SP). Banco de dados hidrometeorológicos. Disponível em: <http://www.sigrh.sp.gov.br/cgibin/bdhm.exe/plu?qwe=qwe>. Acesso em: 29 de fevereiro de 2012.

.INSTITUTO NACIONAL DE PESQUISAS ESPACIAIS. Boletim de monitoramento e análise climática Climanálise. V. 19 - N.10 - out/2004 até V. 20 - N.9 - set/2005. Disponível em: <http://www.cptec.inpe.br/products/climanalise/>. Acesso em: 1 de fevereiro de 2012.

.PREFEITURA MUNICIPAL DE ILHABELA. Dados do município. Disponível em: <http://www.ilhabela.sp.gov.br/>. Acesso em: 1 de fevereiro de 2012.

.INSTITUTO BRASILEIRO DE GEOGRAFIA E ESTATISTICA. Disponível em: <http://www.ibge.gov.br/cidadesat/painel/painel.php?codmun=352040\#>. Acesso em: 1 de fevereiro de 2012.

\section{Documentação Cartográfica}

.INSTITUTO BRASILEIRO DE GEOGRAFIA E ESTATISTICA. Carta topográfica de São Sebastião. - SF 23 - Y - D - VI - 3. Rio de Janeiro: Ed. IBGE, 1991 (1a ed. 1977). Mapa colorido. Escala 1:50.000.

.INSTITUTO BRASILEIRO DE GEOGRAFIA E ESTATISTICA. Mapa de Clima do Brasil. Rio de Janeiro: Ed. IBGE, 2002 ( $1^{\text {a }}$ ed. 1978). Mapa colorido. Escala 1:5.000.000. 